\title{
Dengue transmission and urban environmental gradients
}

\author{
Viroj Wiwanitkit
}

Received: 14 May 2014 / Revised: 4 June 2014 / Accepted: 16 June 2014 / Published online: 27 June 2014

(C) ISB 2014

Sir, the recent report on "dengue transmission and urban environmental gradients" is very interesting (Khalid and Ghaffar 2014). Khalid and Ghaffar (2014) noted that "low elevation areas with calm winds and minimum temperatures higher than the normal, rapid increase in unplanned urbanization, low flow accumulation, and higher drainage density areas favor the dengue transmission (Khalid and Ghaffar 2014)." Of those factors, temperature is widely discussed. Wu et al. (2009) found that in Taiwan, "numbers of months with average temperature higher than 18 degrees $\mathrm{C}$ per year and degree of urbanization were found to be associated with increasing risk of dengue fever incidence at the township level." The emergence of dengue in new settings is difficult for local health care practitioners to diagnose (Wiwanitkit 2010). There is no doubt that environmental factors are very important determinants for dengue transmission. However, as Barcellos and Lowe (2014) noted "both climatic and socioeconomic changes" are needed for effective dengue control.
To successfully manage dengue, environmental, host, and pathogen factors need to be considered, following standard medical epidemiology principles.

\section{References}

Barcellos C, Lowe R (2014) Expansion of the dengue transmission area in Brazil: the role of climate and cities. Trop Med Int Health 19:159 168

Khalid B, Ghaffar A (2014) Dengue transmission based on urban environmental gradients in different cities of Pakistan. Int J Biometeorol. doi:10.1007/s00484-014-0840-6

Wiwanitkit V (2010) Dengue fever: diagnosis and treatment. Expert Rev Anti Infect Ther 8:841-845

Wu PC, Lay JG, Guo HR, Lin CY, Lung SC, Su HJ (2009) Higher temperature and urbanization affect the spatial patterns of dengue fever transmission in subtropical Taiwan. Sci Total Environ 407: 2224-2233

V. Wiwanitkit

Hainan Medical University, Haikou, China

V. Wiwanitkit

Faculty of Medicine, University of Nis, Nis, Serbia

V. Wiwanitkit

Joseph Ayobabalola University, Akure, Nigeria

V. Wiwanitkit $(\bowtie)$

Wiwanitkit House, Bangkhae, Bangkok 10160, Thailand

e-mail: wviroj@yahoo.com 